\title{
VOTOS A FAVOR DEL REGALISMO EN EL ALTO CLERO CHARQUEÑO (SIGLO XVII)
}

Votes in favour of the Regalism in the High Clergy of Charcas (17th Century)

\section{Andrés Eichmann Oehrli*}

Resumen

La reflexión sobre el mejor modo de gobernar y de armonizar las potestades civiles y eclesiásticas tuvo particular impulso en La Plata (hoy Sucre, Bolivia), a fines del siglo XVII. El escrito más importante de ese tiempo es un voluminoso tratado del sardo Pedro Frasso, fiscal de dicha Real Audiencia. Algunos de los más encumbrados personajes de la ciudad (entre ellos cinco eclesiásticos) elogian a este jurista por medio de cartas que son publicadas en los preliminares de ambos volúmenes del tratado. Me interesa: 1) situar estos paratextos en relación con las controversias en torno al regalismo; 2) delinear el perfil de sus autores; 3) poner a la vista sus argumentos; 4) ensayar respuestas a la pregunta por las motivaciones de su adhesión, así, como por las del silencio de otros.

Palabras clave: Administración eclesiástica colonial, regalismo, Audiencia de Charcas.

Abstract

In La Plata (nowadays Sucre, Bolivia), reflections on the best way of governing and harmonizing civil and ecclesiastical authority were of particular interest at the end of the $17^{\text {Th }}$ century. The most important text of that time is a voluminous treatise written by the Sardinian Pedro Frasso, a public prosecutor of the Royal Audience mentioned above. Some of the highest personages of the city (among them five ecclesiastics) eulogized this jurist by means of letters published within the preliminaries to the two volumes of the treatise. I would like 1) to situate these paratexts with regard to the controversies about the regalismo; 2) to outline the profile of the authors; 3) to make their argumentation visible; and 4) to explain the motivations of their adhesion while others remained silent.

Key words: Colonial Ecclesiastic Administration, regalism, Audiencia of Charcas.

\section{INTRODUCCIÓN}

En el siglo XVII, la reflexión política no podía soslayar las relaciones entre Iglesia y Estado, sin duda uno de los grandes temas de la época. No pocos conflictos tuvieron su raíz en una suerte de "doble dependencia" que en la cúpula se volvía inadmisible. Los súbditos de la monarquía española se consideraban legítimamente gobernados por sus reyes, pero a la vez, todos (rey incluido) se reconocían miembros de un espacio más amplio: eran miembros de la república cristiana que abarcaba otros reinos, gobernada por el romano pontífice. El propio rey español reconocía la autoridad del Papa en materia religiosa (a menudo, solamente, en teoría). Las relaciones entre autoridades civiles y eclesiásticas constituyeron un problema crónico, ya desde el siglo IV. ${ }^{2}$

\footnotetext{
${ }^{1}$ Este trabajo se enmarca en el proyecto Red Europea: Autoridad y poder en el Siglo de Oro del Programa Jerónimo de Ayanz del Plan de Formación de I+D 2009-2010 del Gobierno de Navarra. ${ }^{2}$ Habrá que esperar hasta el último tramo del siglo XVIII (la independencia de las colonias británicas de Norteamérica) para hallar un estado que se declara incompetente en materia religiosa.
} 
Los reyes y sus consejeros (civiles y eclesiásticos) se preguntaron qué atribuciones estaban dispuestos a reconocer como propias del romano pontífice. Las reflexiones con las que se pretendió satisfacer esta inquietud en el siglo XVII (con sus muchos antecedentes teóricos y prácticos), generaron un cuerpo de doctrina de perfil peculiar conocido como "regalismo", 3 que Alberto de la Hera -aunque refiere principalmente al regalismo del siglo XVIII, pero lo aplica también a otras épocasdefine como "un sistema de intervención abusiva del Estado en asuntos de Iglesia" (15). Por eso, no es extraño que fuera objeto de grandes controversias con la sede romana.

He centrado mi interés en algunas cartas "de adhesión" a un tratado regalista titulado De regio patronatu Indiarum, escrito en dos tomos (1677-1679) por Pedro Frasso. ${ }^{4}$ Es un trabajo de grandes dimensiones (1224 páginas, tamaño folio) destinado a sostener en el campo teórico y en la práctica jurídica, los privilegios de la corona española en el terreno eclesiástico: privilegios que consistían en el gobierno mismo de la Iglesia en los dominios americanos (Arvizu, 1986a:531).

Las piezas que llamo "de adhesión" son once cartas latinas escritas por personajes de Charcas, y publicadas en los preliminares de los sendos tomos del tratado. Me ocuparé principalmente de los textos firmados por eclesiásticos, que son cinco. Pero antes será necesario poner sobre la mesa algo del contexto "histórico-doctrinal" en el que aparece el tratado de Frasso y, junto con él, las cartas. Tal contexto no era para estos autores el de una lejana controversia que tenía lugar al otro lado del océano. Por el contrario, era una disputa cuyo asiento (no exclusivo, por supuesto) era la ciudad de La Plata (hoy Sucre).

\section{DisPutAS SOBRE EL REGALISMO ViSTAS DESDE CHARCAS (1640-1688) ${ }^{5}$}

Pido paciencia: será necesario abordar la parte árida de estas páginas, antes de llegar a los textos que nos interesan. Reduciré este repaso al mínimo indispensable para una lectura competente de los textos de los autores charqueños. ${ }^{6}$

\footnotetext{
${ }^{3}$ Obviamente, se originó mucho antes. De la Hera sitúa su arranque en la pragmática sanción de Bourges, en 1438. Sus antecedentes remotos pueden buscarse en el hierocratismo de los pueblos anteriores a Cristo, en los que el poder civil absorbía el religioso. En los primeros estados cristianos el gobernante no estuvo dispuesto a admitir que la esfera espiritual escapara a su control, lo cual dio lugar a un problema ante el que se fueron dando diversas posiciones teóricas y prácticas (1963:19ss.).

${ }^{4}$ Frasso fue fiscal de la real audiencia de Charcas desde 1664 hasta 1674. Desde entonces ocupó cargos de relieve en distintos sitios de América, para culminar su carrera como regente del Consejo de Aragón, a partir de 1691, cargo que no sabemos si llegó a ocupar, dado que murió en 1692.

5 "Charcas" designó originariamente una etnia y su hábitat. Más adelante pasó a designar la villa de La Plata (conocida también como Chuquisaca y Sucre) y el corregimiento o el obispado (desde 1609 arzobispado) del mismo nombre, así como la Audiencia y su distrito. Son muy abundantes los documentos coloniales en los que "Charcas" se utiliza como geónimo que se aplica al «territorio y a la población con que aproximadamente nacerá Bolivia (es decir, las Intendencias de La Paz, Santa Cruz, Potosí y La Plata, más las Gobernaciones de Mojos y Chiquitos) (Barnadas, 1989:36).

${ }^{6}$ El regalismo (y el patronato, que es una de sus manifestaciones) ocasionó una literatura jurídica muy abundante en los siglos XVII y XVIII, y en el siglo XX ha dado lugar a innumerables estudios y publicaciones. Me declaro ajeno a este campo, dado que no soy especialista en Historia del Derecho. He evitado en lo posible internarme en las complejas cuestiones que plantea,
} 
Como se sabe, a partir de las bulas alejandrinas de 1493, la corona española adquirió progresivamente "una situación de exclusividad en la dirección de la Iglesia indiana" (de la Hera, 1963:13), lo que supuso una usurpación de las atribuciones del romano pontífice. Alberto de la Hera afirma que "ningún otro país presenta, probablemente, en momento alguno de su historia, un ejemplo más claro de control secular de la vida eclesiástica" (1963:13). Apunta que la sede romana siempre se defendió, luchó y protestó contra las manifestaciones teóricas y prácticas de regalismo en estados europeos, obviamente incluida España; pero, en relación con las Indias, sufrió sin rechistar los diversos modos de usurpación por parte de la monarquía española. De la Hera registra reacciones escasas y esporádicas, y considera que los dos episodios más significativos en este sentido fueron las sucesivas inclusiones en el índice de libros prohibidos de los tratados De indiarum iure, de Juan de Solórzano Pereira en 1642, y De Regio Patronatu, de Pedro Frasso en 1688 (Arvizu, 1986b:33).

Según Francisco de Ayala, en el tratado de Solórzano, "uno de los aspectos más notables [...] está constituido por la doctrina del patronato universal de los reyes de España en materia eclesiástica" (1947:579). Solórzano sostiene la "tesis vicarial", según la cual los reyes de España "ejercitan en Indias la plena potestad canónica disciplinar con implícita anuencia del Pontífice" (Giménez Fernández, 1949:801).

Ante tal pretensión, la Santa Sede reaccionó de inmediato

[...] poco después de la aparición de los dos volúmenes del tratado de Solórzano, se publicó en Roma, en 1641, un escrito de Antonio Laelio, fiscal de la cámara apostólica, en el que se llevaba a cabo una refutación de las ideas fundamentales en materia canónica y en especial algunas extremadas proposiciones acerca del patronato regio y de la delegación apostólica que se atribuían a los reyes de España (Ayala, 1947:579).

El escrito de Laelio ocasionó la inclusión del tratado de Solórzano en el Index. Pero esta condena pontificia fue un fracaso, ya que "la teoría [...] se impondrá a la jurisprudencia indiana y a los tratadistas civiles; los autores eclesiásticos, religiosos y obispos, la aceptarán sin reservas, excepto contadísimas excepciones", según se refiere principalmente al regalismo del siglo XVIII; pero lo aplica también a otras épocas, según Gómez Hoyos — citado por Ayala — pero sin dar referencias (1947:580). Entre ellas están dos personajes de relieve: Diego de Avendaño, S.J., autor (entre otras obras) de los seis volúmenes de su Thesaurus Indicus (Amberes, 1668-1686) y Gaspar de Villarroel, ${ }^{7}$ autor a su vez de la conocida obra Gobierno pacífico y unión de los dos

limitándome exclusivamente a aquello que resulta de utilidad para mi propósito. Por mi parte, no me habría podido anoticiar con acierto sobre estas cuestiones sin la generosa ayuda de Ana Barrero y de José María Mariluz Urquijo, a quienes manifiesto aquí mi agradecimiento.

${ }^{7}$ Agustino. Nació en Quito, se crió en el Cuzco, e hizo su noviciado y estudios en Lima. Ocupó cargos diversos en Potosí y Cuzco entre 1616 y 1626; pasó a España donde fue Predicador Real. Entre 1638 y 
cuchillos, pontificio y regio, publicada en Madrid en 1656-1657, y reimpresa en la misma ciudad en $1660{ }^{8}$ A pesar de las prudentes reservas de estos dos autores, la tesis de Solórzano gozó de enorme aceptación y "dominó a partir de 1660 en la política indiana" (Giménez Fernández, 1944:330).

Según Francisco Javier de Ayala, la obra de Solórzano Pereira y la de Pedro Frasso vienen a ser como dos peldaños en la escala ascendente de las pretensiones de la corona

[...] en Solórzano todavía no se encuentra expresada en toda su plenitud la doctrina del regio patronato indiano con sus derivaciones regalistas. Hay que esperar a Pedro Frasso para ver sistemáticamente concebida y expuesta la multitud de injerencias que el poder político llevó a cabo en el Derecho eclesiástico de Indias. Sin embargo, Frasso no se comprende sin Solórzano y a éste, si por un lado le cabe la primera formulación verdaderamente sólida y científica del Patronato Real, por otro le corresponde la declarada iniciación del regalismo en la ciencia jurídica indiana (581).

Este es el estado de la "cuestión regalista" (a brochazos), en el momento en que los once autores de Charcas escriben sus cartas de "adhesión".

\section{EL CLUB DE FRASSO}

Entre los autores de las cartas podemos distinguir dos grupos: el de los juristas (casi todos oidores de la Audiencia), y el de los eclesiásticos. Como veremos, ambos grupos estaban estrechamente relacionados, al punto que no se puede hablar de "sectores" separados (ni excluyentes).

a) Juristas. En las actas de acuerdos de la audiencia, a lo largo de una buena cantidad de años se ven, junto con la firma de Frasso (fiscal), las de los oidores que lo acompañan con sus cartas: Luis José Merlo de la Fuente, José del Corral Calvo de la Vanda, Antonio Diez de San Miguel y Solier, Juan Jiménez Lobatón, Alonso de Solórzano y Velasco. ${ }^{10}$ Otro miembro de este grupo es Gaspar de Luna. No fue oidor, sino abogado que trabajaba en la misma Audiencia. ${ }^{11}$

1652 fue obispo de Santiago de Chile. Desde ese año pasó como obispo a Arequipa donde construyó la catedral. En 1659 pasó al Arzobispado de La Plata, que gobernó hasta su muerte en 1665 (DHB).

${ }^{8}$ También en 1738 , ya fuera de los años de nuestro interés. Dos antologías de esta obra fueron publicadas en Quito (1943) y Puebla-México (1960) (ver DHB).

${ }^{9}$ Estos epistológrafos no solamente estaban al corriente de lo dicho, sino que tenían motivos para sentirse especialmente vinculados con todos los juristas mencionados aquí: podían considerarse "en casa" junto con las voces más autorizadas que habían intervenido en la controversia.

${ }^{10}$ De los oidores, el que muestra mayor afinidad con el fiscal Frasso es Corral Calvo de la Vanda, quien declara su satisfacción al contemplar como maestro a Frasso, a quien tuvo la fortuna y el alto honor de haber tenido por discípulo en las aulas de Salamanca (Cfr. Eichmann, 2007).

${ }^{11}$ Tuvo gran familiaridad con Frasso, al punto que durante un tiempo (que podemos suponer prolongado) se alojaba en su casa. En 1669 un querellante se quejó de que en la misma vivienda del fiscal Frasso habitara este abogado que defendía a su contrario en un juicio. La audiencia decidió que Luna debía mudarse de casa y no comer con Frasso (Acuerdos, VI-89). 
Hasta aquí podemos observar rasgos comunes en esta parte del círculo de colegas de Frasso: son todos juristas y ocupan la cúpula política del rico y vasto territorio de Charcas o, al menos, (en el último caso) pertenecen a su órbita. Se sienten unidos múltiples lazos, tanto corporativos como personales.

b. Eclesiásticos. Este segundo grupo consta de cinco individuos, de los cuales tres pertenecen al alto clero secular: Juan Bautista del Campo Caro, deán del cabildo catedralicio, provisor, gobernador del arzobispado y un largo etcétera; Manuel de Peñalosa y Mansilla, que alcanzó las mismas dignidades, en tiempos diferentes que el anterior, porque era más joven; Vicente del Corro Zegarra, párroco de San Miguel (Oruro), a la vez que vicario del arzobispado. Los tres son criollos de gran preparación intelectual, condición que parece indispensable para moverse en el círculo del erudito italiano. También, como el resto de integrantes del club, son de ascendencia ilustre. Del Corro Zegarra presenta parentescos notables: es biznieto de una hermana de Alonso de Peralta, arzobispo de La Plata; es descendiente también (por otra línea) de una hermana de Juan de Solórzano Pereira y, por si fuera poco, es hermano de Leonor del Corro Zegarra, esposa de Pedro Frasso, según datos proporcionados amablemente por J. M. Barnadas.

No sólo por ahí puede comprobarse la imbricación de los sectores civil y eclesiástico en las esferas altas. El oidor Antonio Díez de San Miguel y Solier es padre de Antonio $J r$., quien por esos mismos años ya ocupaba cargos de relieve en lo que sería una larga y brillante carrera eclesiástica. Y el caso más llamativo es Luis José Merlo de la Fuente, quien perteneció sucesivamente a ambos sectores. Como vimos, era presidente de la audiencia en 1672; pues bien, en 1678 recibe una real cédula por la que es nombrado chantre de la catedral de Lima (donde llegará a la dignidad de deán), al tiempo que declara extinguida su plaza como oidor de la audiencia (Libros de registros, II núm. 2055). ${ }^{12}$

Los dos últimos integrantes del "club" son miembros del clero regular. Alcanzaron, también ellos, altos cargos en sus respectivas órdenes religiosas: Juan de Vizcarra Maldonado fue provincial de los franciscanos de San Antonio de los Charcas y Juan Manuel de León, mercedario —en 1666 ocupó el oficio de doctrinero de San Cristóbal de Potosí- al firmar la carta era provincial de su orden, con sede en el Cuzco.

\section{UNA CALA EN LOS TEXTOS}

Ahora estamos en antecedentes. Podemos entrar en los textos de las cartas. A pesar de que no ocupan un abultado número de páginas, será preciso limitarse a revisar los tópicos que cumplen la función de justificar y de sustentar el voto regalista de sus

\footnotetext{
${ }^{12}$ Aunque no se pueden descartar otros motivos posibles, este oidor decidió hacerse sacerdote debido a una calumnia y un destierro inmerecidos, junto con una serie de infortunios familiares ocurridos en el transcurso de su destierro. Se le concedió restaurar su honor: antes de recibir un puesto eclesiástico fue restituido como oidor en Charcas.
} 


\section{Andrés Eichman}

autores. Para ser fiel a lo anunciado en el título de este trabajo, tomaré en cuenta las cartas que provienen de los miembros de ambos cleros (haré una sola excepción).

No será superfluo advertir que en estas cartas todos los elementos se disponen en función del elogio. A lo largo de cada uno de los paratextos que nos ocupan, no se hace otra cosa que ponderar con adjetivos o construcciones variadas la excelencia de Frasso y su obra. Si el lector cree alguna vez que podrá pasar a otro registro más entretenido, se equivoca. Solamente si no busca nada más que lo dicho, estará en condiciones de valorar el ingenio, las alusiones eruditas, la competencia de los autores en manejo de los recursos del género epidíctico, etc.

Cualidades de Frasso y de su obra. Todos los epistológrafos ponen de relieve la eminente inteligencia del autor y las virtudes que puso en juego (laboriosidad, constancia, etc.) para defender los derechos del monarca. Inteligencia y virtudes que se manifiestan en el parto de su ingenio: el tratado que por fin esclarece los aspectos oscuros de una materia tan difícil. ${ }^{13}$ Este primer tópico es por fuerza, en estos textos de género epidíctico, el más abundante. Manuel de Peñalosa y Mansilla pondera de manera ingeniosa la exhaustividad y el rigor del tratado de Frasso sobre tema tan polémico

¿Qué cosas puede haber, dignas de atención en cualquier asunto, que no hayas abordado separadamente de una en una, que no hayas pulido con exquisita elegancia y llevado a término con extremada facundia? Y en verdad, eres el primero y el más adelantado en dar vida con un solo aliento a un doble cuerpo, concertando la entera armonía del derecho del Patronato con los registros agudos y graves (1679:6). ${ }^{14}$

El doble cuerpo del que habla son, obviamente, los dos volúmenes del tratado. Recurre a la tradicional asociación del Derecho con la Música, que encontramos ya en las Leyes de Platón, obra en la que son constantes las dilogías que remiten a la vez a las disposiciones legales y a la música. ${ }^{15}$ Peñalosa tiene en mente esta relación, pero la lleva al extremo de comparar a Frasso con Hiagnis quien — según Apuleyo - fue el inventor de la flauta de dos tubos. Al leer el pasaje de Apuleyo, que enseguida cita Peñalosa, se está en condiciones de captar el valor también visual de ese dar "vida con un solo aliento a un doble cuerpo". Remata el pasaje con la exclamación: "¡Oh dulcísimo Anfión del Derecho proporcionado y acordado!" (Peñalosa, 1679:6). ${ }^{16}$ Los dos adjetivos de "Derecho" se aplican a la labor de Anfión-Frasso (Alarcón, 2010:83-84), y

\footnotetext{
${ }^{13}$ La dificultad de la materia es otro tópico al servicio del encarecimiento de la obra; y era tal vez necesario subrayarla para que el inevitable enfrentamiento de la tiara con la corona se mantuviera en una esfera intelectual inaccesible al vulgo.

14 "Quid enim in assumptu desiderabile, quod non attigeris, ornaueris, impleueris, uiritim, floride, ubertim? Et quidem primus primariusque duplex uno spiritu corpus adspirans, tum acumine, cum grauitate totam componens iuris patronatus harmoniam". La traducción de éste y de los demás pasajes latinos es mía.

${ }_{15}$ Algunas de ellas venían facilitadas en griego, porque la palabra nómos designa tanto "ley" como "melodía".

16 "O in utroque aequalis et aequus uolumine dulcissime iuris Amphion!"
} 
ambos son dilógicos: la proporción puede ser musical o de otro orden, y "acordado", remite tanto a los acordes musicales como a la coherencia. Más adelante continúa

¿Qué aspecto de una materia relevante como ninguna otra, siendo de tanta estimación para todos en las Indias, no ha sido desarrollado e incluso agotado en las explicaciones tanto del primero como de este segundo volumen? ¿Qué cosa que pueda ser pensada, en relación con los sutilísimos problemas del Regio Patronato, no ha sido examinada, puesta en su sitio y agotada en su totalidad? Penetrada hasta el fondo la integridad del conocimiento referido a esta materia, lo hace a uno más conocedor y libre de cuidados; como que antes, cuando todavía no estaban a la vista estos libros, nos internábamos en esa temible selva virgen con pie tembloroso e inseguro (1679:7). ${ }^{17}$

Sin tanta riqueza de imágenes, los demás autores prodigan los mismos elogios a Frasso y a su Tratado.

Valor del objeto defendido por Frasso (el patronato). Vicente del Corro Zegarra manifiesta que las páginas de la obra bañan de luz una materia que, habiendo sido antes tan oscura, queda ahora resplandeciente como «por la acción de los rayos del sol [...], para el uso de todos, en beneficio del orbe entero, en apoyo de la mayor potestad de nuestro rey católico (que supere los siglos de Néstor)» (4). ${ }^{18} \mathrm{~A}$ su modo de ver, las atribuciones pretendidas por la corona sobre los asuntos eclesiásticos constituían un beneficio universal: para toda la Iglesia y también para el mundo. La hipérbole es solo aparente. El lector de la época podía estar de acuerdo o disentir, pero en cualquier caso consideraría que la controversia tenía consecuencias de alcance universal. A nadie se le habría ocurrido por esos años que este tema (el derecho del rey sobre el gobierno eclesiástico) pudiera considerarse irrelevante o secundario.

Por su parte, Peñalosa y Mansilla, más aficionado a las imágenes visuales, estima que "el patronato índico resplandece entre las más preciosas piedras de la corona del católico [monarca]" y que es el "más sagrado símbolo de la corona regia americana" (3). ${ }^{19}$ Juan de Vizcarra Maldonado también recurre al símil de las joyas, lo que le lleva a la comparación, muy frecuentada en la época, entre las riquezas americanas y los productos del ingenio: "he aquí el ilimitado bagaje de los tesoros de las Indias.

\footnotetext{
17 "Quid circa materiam commendatissimam, utpote Indiarum potiorem illis uel illis tam primi, quam huius secundi laboris tractatibus non deductum, non exhaustum? Quid circa delicatissima Regii Patronatus theoremata excogitabile, quod non recensitum, digestum exantlatum? Uniuersa materiei doctrina medullitus exarata, iam quamuis peritiorem securioremque reddet, sicut antea, his libris nec dum exhibitis, tremulo nec satis fixo pede intactam adoriebamur siluam".

18 "solis radiis pellucida [...] in communem usum, in totius orbis commodum, in nostri catholici regis (qui Nestorea superuiuat saecula) maiorem potestatis commendationem".

19 "Sacratioris stemmatis americanae regiae coronae". En una nota marginal señala la doble procedencia de la designación del patronato como joya: Juan de Solórzano Pereira, como mediador, y el milanés Camilo Borrelio, como su origen. No es necesario insistir en la relevancia que podía tener para Solórzano (y para Peñalosa) el hallazgo de un extranjero que expresara su acuerdo con estas pretensiones.
} 
Mirad no el ónice, las ágatas, los piropos ${ }^{20} \mathrm{u}$ otras preciosas gemas, sino el tesoro mismo. He aquí el patronato encomendado a tu patrocinio" (1). ${ }^{21}$

El patronato no afecta a ningún derecho pontificio. Juan de Vizcarra Maldonado acude a la máxima del evangelio según la cual hay que dar al César lo que le corresponde y a Dios lo que es de Dios. Se pregunta

si son de Dios todas aquellas cosas que posee el imperio del César, ¿cuáles han de ser devueltas al César que no sean de Dios? Aquellas, en verdad, que son administradas por quienes las gobiernan como lugartenientes de Dios: por Alejandro, Julio, y otros; ciertamente por Fernando y Carlos Quinto César; y por el Segundo (haga Dios que reine con favorables auspicios) Carlos; a este segundo César restituyes las que son del César, también las que le corresponden por derecho de Patronato (1). ${ }^{22}$

A continuación, Vizcarra Maldonado enumera las fuentes de derecho eclesiástico y civil recogidas por Frasso en su tratado, con el fin de satisfacer a ambas instancias, pontificia y regia, y a sus respectivos especialistas

Proporcionas a cada quien las leyes para ambos derechos, como quien encierra la Ilíada de Homero en el pequeño hueco de una nuez: incluyes en este volumen los documentos pontificios, el derecho de patronato hispano, los privilegios eclesiásticos, [...] los más altos títulos austríacos [...]; cualquiera leerá estos y otros documentos, extrayéndolos de la cáscara de este volumen (1). ${ }^{23}$

Vizcarra puede haber leído en Plinio el Viejo (Historia Natural, VII, 21) lo de la famosa "nuez-estuche" de la Ilíada, de la que habría hablado Cicerón. También pudo conocer la tradición por otras vías. En cualquier caso, es digno de notar el ingenio con el que trae a colación la dureza de la cáscara, en contraste con la enjundia del contenido (intelectual) de la fruta, juegos verbales que practican también Peñalosa y Mansilla.

A su vez, Vicente del Corro Zegarra felicita a Frasso por haber logrado que nada se substraiga a la potestad de nuestro rey, preeminente sobre todas, aunque la separas del derecho pontificio y eclesiástico; de modo que, quedando éste indemne, te manifiestas gran servidor del rey a la vez que gran católico, pues nada afirmas si no lo que sancionan los documentos

\footnotetext{
${ }^{20}$ Piropo: es una aleación de cuatro partes de cobre y una de oro.

21 "en gazarum indicarum immensa suppellex, en thesaurorum non onyx, achates, pyropus, aut pretiosae aliae gemmae, sed thesaurus ipse. En patronatus patronatum tibi commissum".

22 "Si ergo Dei sunt quaeque Caesaris imperium possidet, quaenam reddenda sunt Caesari, quae non sint Dei? Illa sane, quae Dei tenentibus uices dilargita sunt ab Alexandro, Iulio, et aliis; utique Ferdinando, et Quinto Carolo Caesari, et quae Secundo (faxit Deus secundis regnet auspiciis) Carolo, Caesari Secundo reddis, quae sunt Caesaris, et quae iure Patronatus sortitur".

23 "Utrique iuri ius cuique dilargiris, et uelut qui Illiadam Homeri paruo nucis concauo occlusit, uolumine hoc contines Pontificia diplomata, Hispanicum Patronatum, Ecclesiasticas immunitates, Regalia iura, maiora Austriadum stemmata, qualia nec ad Imperatorias infulas, nec ad alterius Monarchiae gloriam euecta sunt; haec et alia e cortice uoluminis euiscerata quisque leget".
} 
pontificios, nada si no lo que en ellos se funda y es conforme a derecho; y al tiempo que distingues el derecho pontificio del regio, dando como con vara dorada de senador a cada uno lo suyo $[\ldots](4){ }^{24}$

Juan Manuel de León expresa lo mismo del siguiente modo

mientras tú examinas la causa del Rey, no hay peligro de que se introduzca ningún daño al derecho eclesiástico y sagrado sino que, con la virgen Astrea, se tributa tanto al imperio del rey como al dominio del pontífice todo aquello que con santo derecho corresponde a cada cual (2). ${ }^{25}$

Descalificación de quienes impugnan el regalismo. Estos autores sabían muy bien que el patronato regio y demás privilegios que se arrogaba la monarquía española estaban lejos de suscitar un acuerdo general entre los estudiosos del Derecho. Era, pues, necesario tomar posiciones frente a la postura contraria. Juan Bautista del Campo Caro desea que la obra de Frasso constituya el remedio "para aplacar las más arduas controversias", y espera que no sea atacada por quienes carecen "de la luz de la sabiduría" (3). ${ }^{26}$

El mejor ejemplo de este tópico corresponde a Antonio Diez de San Miguel (que no pertenece al grupo clerical: es la excepción que anuncié arriba). Dice que

ciertamente algunos reinos extranjeros, gentes extrañas, naciones lejanas, afectan ignorar los privilegios hispánicos, las regalías regias, y los combaten; pero ante ellos ahora quedarán patentes, abiertos, realzados y suficientemente reconocidos (1). ${ }^{27}$

Más adelante añade que tales privilegios quedarán claros incluso "para todos los que deshonestamente les son contrarios y soportan de mala gana las regalías sagradas" $(5) .^{28}$

Para Diez de San Miguel, nadie puede en su sano juicio negar los privilegios de la corona en este ámbito, a menos que lo haga de mala fe.

\section{CONCLUSIONES}

Alguna vez se me ocurrió preguntarme si es posible que a alguno de nuestros autores lo tuviera sin cuidado la discusión teórica sobre el patronato regio. Pienso

\footnotetext{
24 "ut in omnibus praeeminenti regis nostri potentiae nihil subripiatur; ita tamen illam a pontificio et ecclesiastico iure secernis, ut indemne hoc, si magnum regis ministrum, magnum etiam catholicum te ostentes, nihil enim nisi pontificiis diplomatibus sanctum, nihil nisi iuri ipsis innixo consentaneum adstrueris, et dum ius pontificium a regio distinguis, aurea quasi senatoria uirga sua cuique tribuens [...]".

25 "cum regiam causam pertractas, nulla admiscetur iniuria circa acclesiasticum sacrumque ius, sed cum Astrea Virgine tam regis imperio quam pontificis dominio tribuitur quidquid sancto iure unumquodque meretur". Para el simbolismo de Astrea, ver Alarcón (2010:82-83).

26 "ad maximas controuersias sedandas"; "sapientiae luce carentes".

27 "Hispanica privilegia, regias regalias [...] quae quidem affectant ignorare, atque aduersari extera regna, peregrinae gentes, remotae nationes, inter quas iam peruia, atque distincta, satisque nota patebunt".

28 "Omnibus male aduersis, aegreque ferentibus regalias sacras".
} 


\section{Andrés Eichman}

que es perfectamente posible. En ese caso el interesado manifestaría su adhesión a las tesis regalistas por simple cortesía, por divertimento erudito o bien para figurar junto con el brillante Frasso en un libro de alto nivel intelectual. Sin descartar que en algún caso esto pudiera resultar acertado, parece que, al menos para la mayoría de los miembros del "club", los móviles fueran distintos.

Es muy probable que advirtieran como algo único (lo fue de hecho, en su siglo) el ver abierta para ellos, la oportunidad de intervenir en una controversia de alcance mundial que se venía desarrollando desde la década de 1640 en el máximo nivel. Estaban familiarizados con ella y con algunos de sus principales protagonistas, de quienes podían considerarse paisanos. La ocasión la pintan calva: no desdeñarían la ocasión de hacerse oír, siquiera desde un puesto secundario (los preliminares del tratado). Y sospecho que expresaron lo que sentían.

Por otra parte, el abultado número de cartas de adhesión permite pensar en un interés compartido. Es posible que estos eclesiásticos desearan corresponder personal y/o corporativamente a un régimen que les dio acceso a puestos de privilegio. Comadrán Ruiz afirma que el clero criollo participó ampliamente en la administración eclesiástica, ya desde el siglo XVI

Esa participación cada día más notable del clero criollo en los distintos estratos de las diferentes misiones de la Iglesia en América — y aún en la misma península - significó, a su debido tiempo, y una vez que fue adquiriendo prestigio en todos los órdenes, y por ende llenando los requisitos que en la época se exigían para ello, que [los clérigos criollos] fuesen propuestos por el rey y por el consejo de indias para ocupar distintas sedes episcopales y arzobispales (1989:77). ${ }^{29}$

No les faltarían motivos para ver con ojos favorables las tesis regalistas. Y sin meterme a adivinar intereses ocultos, quizá fueran conscientes que, de tal apoyo, podría resultar un beneficio adicional.

En este sentido, acaso no sea descabellado pensar que pudo haber algún tipo de conexión entre las cartas del "coro regalista", y el nacimiento de la carrera de Derecho en la Universidad de San Francisco Xavier de Chuquisaca, en la misma ciudad, poco más de un año después de la publicación del segundo volumen del tratado de Frasso. Fundada en 1624, es precisamente en 1681 cuando comienzan los estudios en Leyes. La coincidencia de fechas puede muy bien ser casual, pero es indudable que la corona pudo, gracias a las cartas, conocer la adhesión de los funcionarios civiles y eclesiásticos a la doctrina regalista. Se puso de manifiesto que en la ciudad había juristas competentes, que estaban al tanto de las últimas novedades en relación con las controversias del momento: como que varias de estas (sobre todo, su culminación) se habían escrito en La Plata. La ciudad bien podía ser considerada un bastión regalista.

\footnotetext{
${ }^{29} \mathrm{El}$ autor ofrece datos de 216 obispos y arzobispos criollos (principalmente en América; porque los hay que fueron enviados a Filipinas, a la península, etc.) del periodo colonial.
} 
Los silencios también resultarían elocuentes: como era de prever, no se sumó a este coro ningún jesuita. Las tensiones que previsiblemente habían de suscitar las tesis de Frasso entre la corona y el papado hacían impensable que un miembro de la Compañía adhiriera a su tratado, por consideración a su cuarto voto, de obediencia al romano pontífice. Carlos Gálvez-Peña (2006) explica cómo la Compañía, al revelarse defensora de un orden cristiano por encima de las regulaciones del Estado, conoció progresivamente la animadversión de la corona, hasta llegar a la expulsión en 1767.

Pues bien: la Universidad platense estaba a cargo de la Compañía de Jesús, y la creación de las dos cátedras de Cánones y de una tercera de Instituta fue iniciativa del arzobispo Castilla y Zamora, quien impuso su voluntad en contra de la de los jesuitas (DHB), los cuales jamás se hicieron cargo de esas materias. Puede pensarse que albergarían de muy mala gana tales cátedras, pero no tuvieron la oportunidad de rechistar: el arzobispo, en su afán de dar personalmente impulso a los nuevos estudios, no solamente dotó económicamente las cátedras, sino que, como doctor en cánones por la Universidad de Granada (España), se integró al claustro docente (Abecia, 1939:252).

De modo que, aunque la hipótesis aquí aventurada no tuviera asidero (en contra de las apariencias hoy visibles), sí puede pensarse en una alianza, en un apoyo recíproco, motivado ya por convicción intelectual, ya por conveniencia.

$$
\begin{array}{r}
\text { Universidad de Navarra* } \\
\text { Grupo de Investigación Siglo de Oro (GRISO) } \\
\text { Campus universitario s/n } \\
31009 \text { Pamplona-Navarra (España) } \\
\text { aeichmann@unav.es }
\end{array}
$$

BIBLIOGRAFÍA

Abecia, Valentín. Historia de Chuquisaca. Sucre: Charcas, 1939.

Alarcón, Estela. "Motivos mitológicos en epistológrafos de Charcas", en Classica Boliviana. Actas del V Encuentro Boliviano de Estudios Clásicos. La Paz: Plural, 2010:77-87.

Acuerdos de la Real Audiencia de La Plata de los Charcas. J. M. López Villalba (Dir.). Sucre: Corte Suprema de Justicia / Agencia Española de Cooperación Internacional para el Desarrollo / Archivo y Biblioteca Nacionales de Bolivia, 2007 (10 vols.).

Arvizu y Galarraga, Fernando de. "Don Pedro Frasso y la inmunidad eclesiástica (16841685)", en $A H D E \mathrm{~N}^{\circ}$ 56. (1986a):521-541.

------ "El pensamiento regalista de don Pedro Frasso en su obra De Regio Patronatu Indiarum", en Revista Chilena del Derecho No 12. 1986b:29-51.

Ayala, Francisco Javier de. "Ideas canónicas de Juan de Solórzano (el tratado De Indiarum iure y su inclusión en el Índice)", en Anuario de Estudios Americanos $\mathrm{N}^{\circ} 6$. (1947):579-613.

Barnadas, Josep Maria. Es muy sencillo: llámenle Charcas. Sobre el problema de los antecedentes coloniales de Bolivia y de su histórica denominación. La Paz: Librería Editorial Juventud, 1989.

Campo Caro, Juan Bautista del. "D.D.D. Petro Frasso, Regiae Platensis cancellariae Senatori perillustri [...]”, en Frasso. De Regio Patronatu ac aliis. Madrid: Fernández Buendía, $1677, \mathrm{~s} / \mathrm{n}$. 
Comadrán Ruiz, Jorge. "Los sacerdotes criollos y las prelaturas indianas durante el periodo hispano", en Revista de Historia Americana y Argentina $\mathrm{N}^{\circ}$ 29-30. (1989):75-135.

Corro Zegarra, Vicente del. "Nobilissimo ac sapientísimo uiro, integerrimo consuli [...]", en Frasso. De Regio Patronatu Indiarum. Madrid: Fernández Buendía, 1679, s/n.

Diez de San Miguel, A. "Optimo atque sapienti senatori [...]", en Frasso. De Regio Patronatu ac aliis. Madrid: Fernández Buendía, 1677, s/n.

DHB: Diccionario Histórico de Bolivia. Josep Maria Barnadas (dir.). Sucre: Grupo de Estudios Históricos, 2002.

Draper, Lincoln. Arzobispos, canónigos y sacerdotes: interacción entre valores religiosos y sociales del clero de Charcas del siglo XVII. Sucre: Archivo y Biblioteca Arquidiocesanos "Monseñor Taborga", 2000.

Eichmann, Andrés. "Textos encomiásticos latinos en Charcas", en Classica Boliviana; Actas del IV Encuentro Boliviano de Estudios Clásicos. Cochabamba: SECRAD, 2007:29-54.

Frasso, Pedro. De Regio Patronatu Indiarum quaestiones aliquae desumptae et disputatae in alia quinquaginta capita partitae. Madrid: J. Fernández Buendía, 1679 (t. II).

----- De Regio Patronatu ac aliis nonnullis regaliis, regibus catholicis in indiarum occidentalium imperio, pertinentibus [...]. Madrid: J. Fernández Buendía, 1677 (t. I).

Gálvez-Peña, Carlos. “¿Dios y el rey? La prédica jesuita y la Corona en el Perú del siglo XVIII", en La formación de la cultura virreinal (III: El siglo XVIII). K. Kohut y S. Rose (eds.). Madrid-Frankfurt: Vervuert-Iberoamericana, 2006:205-230.

Giménez Fernández, Manuel. "Las regalías mayestáticas en el derecho canónico indiano. (Apuntes para desarrollar una lección del programa de instituciones canónicas en el derecho indiano)", en Anuario de Estudios Americanos No 6. (1949):801-811.

------ "Nuevas consideraciones sobre la historia, sentido y valor de las bulas alejandrinas de 1493 referentes a las Indias", en Anuario de Estudios Americanos № 6. (1944):173-429.

Hera, Alberto de la. El regalismo borbónico y su proyección indiana. Madrid: Rialp, 1963.

Laelio, Antonius. Observationes ad tractatum De Indiarum iure Ioannis de Solorzano Pereira. Romae: Ex Typographia Reuerendae Camerae Apostolicae, 1641.

León, Juan Manuel de. "Disertissimo iurium Moderatori, multis nominibus Consuli Venerando", en Frasso. De Regio Patronatu ac aliis. Madrid: Fernández Buendía, 1677, s/n.

Libros de registros-cedularios de Charcas (1563-1717). Buenos Aires: Instituto de Investigaciones de Historia del Derecho, 1972 (5 vols.).

Losada, Ángel. "Diego de Avendaño S.I. moralista y jurista, defensor de la dignidad humana de indios y negros en América", en Missionalia Hispanica $\mathrm{N}^{\circ}$ 115. (1972):1-18.

Mariluz Urquijo, José María. "La predicación rioplatense frente al poder durante el siglo XVIII", en Revista de Historia del Derecho N ${ }^{\circ} 34$. (2006):191-212.

Peñalosa y Mansilla, Manuel de. "Perillustri ac consultissimo Domino [...]", en Frasso. De Regio Patronatu Indiarum. Madrid: Fernández Buendía, 1679, s/n.

Vizcarra Maldonado, Juan de. "[...] Sapientissimo iurisconsulto, meritissimo platensis cancellariae regi fisci patrono [...]”, en Frasso. De Regio Patronatu ac aliis. Madrid: Fernández Buendía, 1677, s/n. 